Georgia State University

ScholarWorks @ Georgia State University

\title{
Artificial intelligence in educational leadership: a symbiotic role of human-artificial intelligence decision-making
}

Yinying Wang

Georgia State University, ywang103@gsu.edu

Follow this and additional works at: https://scholarworks.gsu.edu/eps_facpub

Part of the Education Commons, and the Education Policy Commons

\section{Recommended Citation}

Wang, Yinying, "Artificial intelligence in educational leadership: a symbiotic role of human-artificial intelligence decision-making" (2021). Educational Policy Studies Faculty Publications. 42.

https://scholarworks.gsu.edu/eps_facpub/42

This Article is brought to you for free and open access by the Department of Educational Policy Studies at ScholarWorks @ Georgia State University. It has been accepted for inclusion in Educational Policy Studies Faculty Publications by an authorized administrator of ScholarWorks @ Georgia State University. For more information, please contact scholarworks@gsu.edu. 
Artificial Intelligence in Educational Leadership:

A Symbiotic Role of Human-AI Decision Making

Yinying Wang*

Georgia State University

Yinying Wang is an assistant professor of Educational Leadership in the Department of Educational Policy Studies at College of Education and Human Development in Georgia State University. Her research interest intersects technology, neuroscience, social network analysis in educational leadership and policy, and leaders' decision making.

* Correspondence concerning this manuscript should be addressed to:

Yinying Wang

Georgia State University, 30 Pryor Street, Room 420, Atlanta, GA 30302-3977

Email: ywang103@gsu.edu 
Artificial Intelligence in Educational Leadership:

A Symbiotic Role of Human-AI Decision Making

The fields of educational leadership and artificial intelligence (AI) have been growing up together, and mostly growing apart till the late 2010s. As AI forges ahead, what is the role of AI in educational leadership? This position paper aims to explore the answer to this question. This paper focuses on the role of $\mathrm{AI}$ in a fundamental element of educational leadership being decision making which includes leaders' individual decision making and organizational decision making. To do so, I synthesized the interdisciplinary literature that intersects AI, decision making, and educational leadership.

The paper unfolds as follows. I first define what AI is, followed by an overview of educational leadership in an age of AI. The discussion of AI is grounded in the conceptualizations of decision making as the foundation of education leadership, followed by an elaboration of the impact of AI on two prevalent decision-making approaches in educational leadership: data-driven, evidence-informed decision making, and value-based moral decision making. The paper concludes with recommendations for educational leadership practitioners and researchers.

\section{What Is Artificial Intelligence?}

The history of both fields of educational leadership and AI can be traced back to the 1950s (Wang, 2017). In the 1950s and 1960s, decision making was one of the four major theories in educational leadership (Griffiths, 1959). In a broader field of administrative science, celebrated Nobel Laureate Herbert Simon advanced the research on organizational decision making by proposing bounded rationality and uncertainty in decision making (Simon, 1972). Meanwhile, in the wake of breakthroughs in AI research in the 1950s, Simon (1965) boldly 
predicted that smart machines would be capable of achieving any work that a human could do by 1985. In hindsight, the early audacious prediction of AI overestimated automation but underestimated the unique, complementary strengths of $\mathrm{AI}$ and humans in decision making (Jarrahi, 2018). After the early days marked by overpromising and under-delivery, the field of AI has made rapid strides in developing intelligence in decision making over the last few decades (Russell, 2019).

What is AI exactly? AI refers to a type of algorithms or computerized systems that resemble human intellectual processes, such as the ability to uncover meaning, reason, and learn from past experiences (Castelvecchi, 2016). To acquire such intelligence, there are four technical approaches: rule-based approach (i.e., if X, and then Y), machine learning (i.e., statistical techniques), neural networks, and deep learning (Davenport, 2018). The former two approaches have already been adopted in school leaders' decision making in many areas, ranging from instruction coordination and evaluation, curriculum development, high school dropout prevention, to school improvement (Duke, 2019; Sara et al., 2015).

The latter two approaches (i.e., neural networks and deep learning) are new to educational leadership. Neural network bears a close resemblance to human brains' mental processes, hence the "neural network" moniker (Ullman, 2019). The neural networks of AI emulate how billions of brain cells (i.e., neurons) and different sets of brain regions (i.e., neural networks) communicate with one another by developing many artificial neurons interconnected via weighted links that receive, process, and transmit information. Processing massive amounts of information, the neural networks identify the patterns within data, optimize the processing and analysis of future data, and then make adaptive decisions based on real-time data. To further boost analytical efficiency, we use a technical approach in AI called deep neural learning, also 
known as deep learning. Deep learning allows multiple processing units and layers to process, learn, and represent data (Ullman, 2019). Therefore, deep learning AI programs take enormous computing power and can outperform humans in identifying faces, recognizing speech, and many other tasks. Some school leaders have decided or planned to use facial recognition software as part of efforts to beef up school safety (Klein, 2019).

Taken together, $\mathrm{AI}$ is a comprehensive term for different technical approaches. To produce accurate results, AI often requires copious amounts of data, as the data "train" the algorithms to detect patterns (Wang, 2020). More important, with more data feeding into AI algorithms, AI can improve over time. In the quest to build more powerful algorithms to extract patterns in data, AI researchers need ever greater amounts of data and computing power. With more data, voice assistants (e.g., Siri and Alexa) and auto-complete suggestions in text messages and emails are more accurate. In school leadership preparation, AI can be used to train leaders by providing real-time feedback on their decision-making skills. Consider school principals' decisions on how to allocate school budget. The autocomplete of a trainee's future decisions can be predicted by using all relevant historical data—how principals have made similar decisions over time. If a school principal trainee is about to make a decision that is inconsistent with other leaders' past decisions, AI can flag the discrepancy. The trainee can then reflect on his or her decision to either yield to the predicted decision or provide a compelling argument to override the prediction. AI has already been developed to predict judges' asylum decisions with about $80 \%$ accuracy on the date a case opens. AI developers also added learning functionality to the AI system, which enabled it to simulate the decision-making of an individual judge by drawing on that judges' past decisions (Babic et al., 2020). 
To develop such AI systems, available data and rules are essential. The importance of data and rules in $\mathrm{AI}$ is where AI comes into play in educational leadership, particularly in the invisible, mental processes of making decisions and the ensuing observable behaviors in educational organizations.

\section{AI and Educational Leadership}

AI has often been discussed as a harbinger of an unprecedented wave of automation, thereby shifting the distribution of labor among occupations and industries and re-shaping future jobs (Frank et al., 2019). More than a third of the jobs U.S. students favored are considered at high risk of being automated in the next 15 years (Zeira, 2018). Over the next ten years, AI is expected to automate $40 \%$ of the tasks that teachers now perform, especially non-instructional tasks such as tracking student progress (Herold, 2019). Moreover, instructional tasks could be reshaped by AI-powered classroom management tools and tutors that provide personalized instruction and adaptive testing (Sparks, 2017). In a survey, 44\% of teachers thought AI could help in repetitive, time-consuming tasks, such as taking attendance and making copies (Bushweller, 2020). A recent report predicted that AI could free up about one-third of teachers' working hours (13 hours/week; Bryant et al., 2020) for more human-driven tasks such as focusing on one-on-one relationships to inspire students and collaborate with colleagues. These tasks are emotionally rewarding, having the potential of reducing teacher burnout which has been challenging for school leaders.

In educational leadership, AI has received scant attention. Although there have been endeavors of using simulation in educational leadership preparation (Dexter, 2020), very limited literature has elaborated on how AI and educational leadership fit together. Against this background, this paper aims to elaborate on the role of AI in educational leadership. I try to look 
beyond the sensational hyperbole surrounding AI that has led many to believe that AI will soon outthink humans. Typically, current AI applications are considered as narrow AI, which performs a precisely defined task, such as screening candidates for the position of school principal by identifying certain patterns in job application materials (Jacob et al., 2019). The current $\mathrm{AI}$ is far from a bold vision of general $\mathrm{AI}$ that aims to build a computerized system that has all the physical and intellectual capabilities of a human being (Bostrom, 2016), such as reconciling the tension as school leaders decide how to allocate finite resources to serve the best interests of one student and the best interests of all students (Frick et al., 2013). At least for now, the likelihood is remote that transcendent super-intelligent computerized systems will soon be able to learn, imitate, and replicate personal experiences, subconscious thoughts, and personalities of humans (Buchanan and O'Connell, 2006).

$\mathrm{AI}$ in education leadership is less about technical problems but more about a leadership process. Placing AI in educational organizations, I conceptualize a symbiotic role of human-AI decision making, which is subject to the influence of decision makers' individual predispositions (e.g., risk-averse vs. risk-seeking), core values, access to data and information, and social influence. The symbiotic role of human-AI decision making is executed through leader behaviors at the individual, dyadic, and group levels, which then influence organizational performance moderated by school context (e.g., government and policy, economy, community, and stakeholders). In this section, I first elaborate on the importance of decision making — both leaders and organizational decision making, followed by a discussion of the symbiotic role of human-AI decision making which could have a profound impact on organizational performance. 


\section{Decision Making as the Foundation of Educational Leadership}

Decision making — choosing a course of action out of a choice set - is the foundation of educational leadership (Wang, 2021). Educational leadership is "a general, abstract application of decision making" (Tarter and Hoy, 1998, p. 212). Specifically, educational leadership is shaped by (1) leaders' decisions, which are made by individual leaders, and (2) organizational decisions, which are made by organizational members who are subject to the influence and authority of leaders in terms of how organizational members collect and process information for decision making.

Endowed with power, decisions made by leaders have higher stakes than other organizational members. Leaders' decisions are influenced by an array of factors, including individual predispositions (e.g., risk-averse vs. risk-seeking), leaders' core values (e.g., group interest over self-interest), data and information available at the moment of making decisions, and social influence (e.g., an aggressive, demanding school board or a deferential board). Together, these factors shape school leaders' decisions, which are then carried out through behaviors; therefore, leader behaviors are an outward manifestation of leaders' decision making (Sergiovanni, 1992). A pattern of leader behaviors is conceptualized as a leadership style, such as transformational leadership, instructional leadership, social justice leadership, and many others. These leadership styles then exert influences at the individual, dyadic, and group levels in organizations, which influence organizational outcomes such as school performance outcomes.

Due to constraints of time, expertise, and policy, it is impossible for a leader to make every single decision in an organization. It is thus necessary for leaders to empower other organizational members to make and implement decisions. Decisions in organizations sometimes are made as a group (i.e., a committee, panel, task force, or an ad hoc group). Once a leader 
empowers a group to make decisions, the leader's task shifts from making individual decisions to developing decision-making rules and procedures that ensure the group makes wise decisions by marshaling collective wisdom. Counterintuitively, the need to delegate decision-making power to others goes against humans' innate preference for control and autonomy (Lammers et al., 2016). This explains why in schools, principals have difficulty with sharing their decision-making power with teachers (Weiner, 2016). To empower organizational members to make quality decisions, it takes more mental efforts for leaders to suppress their innate desire for control and autonomy than making a fast, reflexive, desire-driven decision. Further, organizational decisions are not isolated cases. Rather, one member's decision becomes the input for another member to make a decision (Simon, 2013). Each decision contributes to a cumulative effect of a stream of decisions or indecisions (i.e., chronic incapability of making decisions). As a result, organizational decisions yield organizational behaviors, and vice versa.

With the understanding of a fundamental role of decision making — both leaders' individual decision making and organizational decision making —in educational leadership, one may wonder: What does AI have to do with school leaders' decision making? I envision a symbiotic role of human-AI decision making in educational leadership.

\section{The Symbiotic Role of human-AI Decision Making}

Humans — school leaders and organizational members included — and AI can make better decisions than either one alone. How can humans and AI be complementary in both school leaders' decision making and organizational decision making? To answer this question, let us start with leaders' decision making. In human decision making, our sensory systems (i.e., sight, hearing, touch, smell, and taste) collect incoming information, which is then processed by the brains' different systems, including the attentional system, memory system, motivational system, 
emotional system, and cognitive system. After processing the incoming information, human brains take a winner-takes-all approach to generate a decision, which is then executed through behaviors via muscular movements to engage in verbal and nonverbal communication (Wang, 2021). In this process, AI — with its efficiency and brute force of computational power — can complement data-driven, evidence-informed decision making. Human judgment, on the other hand, is superior to AI in making value-based moral decisions.

Data-driven, evidence-informed decision making can be complemented by AI-assisted decision making.

With its efficiency in collecting, processing, analyzing data, and providing real-time or near real-time results, AI can bring in analytical efficiency to assist school leaders in making data-driven, evidence-informed decisions. Data-driven, evidence-informed decision making has been a prevailing decision-making approach for school leaders (Wang, 2020). Massive amounts of data (e.g., test scores, student and employee demographics, and ratings and comments in employee job performance evaluation) have been collected by education agencies at the federal, state, and local levels. School leaders often face complex situations that are characterized by an abundance of factors. More important, these factors are not necessarily in linear relationships but are "multi-level, processual, contextual and interactive" (Marion and Uhl-Bien, 2001, p. 631). Such complex organizational systems demand the processing of masses of information, which consumes enormous cognitive capabilities.

However, school leaders' cognitive capacities are finite-with limited supply. This is because performing cognitive functions in human brains is metabolically expensive. Cognition is a finite resource in human brains. Anything that consumes limited cognitive capacity leaves decision makers with less cognitive capacity for making the next decision. Each day offers a 
barrage of information in which school leaders may find insights. Yet making too many decisions and holding too much information in memory drain the limited cognitive resources. Stress, hunger, and fatigue further undermine cognitive functions in school leaders' brains. As a result, making decisions takes a cognitive toll on school leaders.

The constrained cognitive capacity can be complemented by AI with its superior quantitative, computational, and analytical capabilities. Endowed with ever-growing computational processing power and real-time data, AI can efficiently retrieve and analyze massive amounts of data and provide real-time or near real-time results to assist school leaders in making data-driven, evidence-informed decisions. In addition to numeric data, there are also many other types of data that can be leveraged by decision makers in educational organizations, including text, images, videos, audios, social media hashtags, posts, comments, likes, and retweets, and even data from wearable sensors that record a person's sleep patterns and muscular movements (Wang, 2016). More important, the copious amounts of data in the educational system are generated constantly, laying a strong foundation for school leaders to use AI to assist in turning data into actionable information in real time. In Denmark, researchers have conducted a research study to predict high-school dropouts with machine learning (Sara et al., 2015).

Despite available data and evidence, school leaders often must make decisions in the face of uncertainty. Uncertainty is characterized as inadequate information about all alternatives or their consequences (Choo, 1991). Under uncertain circumstances, AI can assist school leaders in predictive analytics by identifying relationships among many factors and by data-driven statistical inference approaches to inferring the probability of an outcome of each option. In the United States, using longitudinal student records data from the North Carolina Department of Public Instruction, researchers applied machine learning techniques and incorporated 74- 
predictor measures from Grades 3 through 8, including academic achievement, behavioral indicators, and socioeconomic and demographic characteristics to identify students at the risk of dropping out of school and provide intervention accordingly (Sorensen, 2019). However, leaders can use AI to reduce uncertainty—only to some degree. Uncertainty can never be fully eliminated at the moment of decision making. Uncertainty is inherent in decision making, especially at the moment of decision making when school leaders have no benefit of hindsight. When the uncertainty is overwhelming — as is the case when organizations are faced with situations for which there is no precedent, a data-driven, evidence-informed decision-making process would become insufficient for school leaders. Moreover, what should a school principal decide with a probability of $52 \%$ - or even $98 \%$ - that a student will drop out of a school? Should the leader invest more resources in that student or less? If a teacher is labeled as "ineffective" in the teacher evaluation system, should a principal decide to terminate the teacher's employment or provide the teacher with more coaching and professional development? Does the fact that the teacher's spouse serving on the school board change the principal's decision? Under such circumstances, a value-based moral decision-making approach may prove more helpful, as we will see in a moment.

Before venturing into value-based moral decision making, here I engage in a discussion on how to use data in AI-assisted decision making - an issue that has raised many questions. Data may give people an illusion of objectivity. In the context of educational leadership, data should be considered as social information, which is dependent on who generates them, who uses them, and for what purpose. There are many lurking biases in current AI, if used without human judgment, that could be amplified. Biases refer to predictable, systematic errors in decision 
making, and they are mostly at work beneath the threshold of our consciousness (Kahneman, 2013). AI is created by humans who may not even be aware of their own unconscious biases. The sources of biases in AI mostly lie with a dataset called training data. Using the training data, AI algorithms test and validate the techniques, which were introduced earlier in the paper, to answer questions or make predictions about cases that are not contained in the training data, but in another dataset called testing data. Since the training data are a reflection of social and cultural phenomena, they are rarely bias-free (Courtland, 2018). Systemic biases in society could lead to biases in the training data used in the development of AI algorithms to assist school leaders in their data-driven, evidence-informed decision making. That is, the data that feed into AI programs can also be biased. Data, despite the appearance of objectivity, do not protect school leaders from making biased, erroneous decisions. I will circle back with examples of an array of biases in existing AI algorithms. But now I turn to the matter of value-based moral decision.

\section{Value-based moral decision making may run against AI-assisted decision making.}

A value-based moral decision-making approach means that school leaders use their moral values as a guide when they navigate a fog of uncertainty. Moral values assert "oughts" in decision making, which may not be reduced to data points (Simon, 2013). For example, many school leaders felt it was wrong to have uniform expectations for student achievement (Frick, 2009). For school leaders, to make moral decisions is to promote cooperation in schools and communities by espousing five moral values: (1) the ethic of justice (e.g., fairness, equity, due process, and responsibility for the common good), (2) the ethic of care (e.g., empathy, compassion, and treating people as ends but not means), (3) the ethic of critique (e.g., moral concerns over institutionalized injustice that disproportionately benefit some groups over others 
as a result of political, economic, and judicial power shaped by history), (4) the ethic of community (e.g., taking into consideration the values, beliefs, history, and desire of the community), and (5) the ethic of profession (e.g., professional practices and standards; Shapiro and Stefkovich, 2016). These moral values serve as a beacon in leaders' decision making as they navigate uncertainty.

More important, value-based moral decision making may run against AI-assisted datadriven, evidence-informed decision making. First, lurking biases in data may clash with valuebased moral decision-making. Take teacher hiring as an example. To make hiring decisions, the traditional approach is to pore over resumes, credentials, and recommendations, assemble a panel for job interviews, and may even consider personality test results. Recently, scholars have developed a screening tool that made recommendations about a job candidate who was a good fit for the teaching position, based on teachers' resumes, teacher evaluations, and retention data (Jacob et al., 2019). The screening tool generated a ranking of all applicants based on each applicant's score that included the experience listed on resumes, the recommendations from references, and the district's history of all hired teachers. Then, school principals looked at the applicants who have met a particular cutoff score and did another round of evaluations before bringing prospective teachers in for face-to-face interviews. Despite the analytical efficiency, this approach to making hiring decisions is fraught with gender and racial biases.

To date, most teachers (79.3\%) and school principals (77.7\%) in the United States have been White (National Center for Education Statistics, 2019). Using existing resumes of teachers and school leaders to build an AI program for hiring means the AI may favor White applicants, thereby magnifying racial bias. This is not just a thought experiment because a real-life lesson from Amazon.com Inc.'s AI has already offered a cautionary tale. In 2014, the company used its 
received resumes over a 10-year period and built an AI program for hiring. The AI program reviewed applicants' resumes, gave candidates scores, and ranked the candidates by the scores. The company soon realized gender bias in its hiring AI, which was developed to review applicants by observing patterns in the existing resumes. Most resumes used to develop the AI program came from men, reflecting male dominance in the technology industry. The AI program taught itself that male candidates were preferable, penalizing resumes that included the word “women" and even downgrading graduates of all-women's colleges (Dastin, 2018). Given the demographic makeup of educators, AI programs may favor certain gender or racial groups, which clash with the values advocated in education.

In addition to lurking biases in AI programs, another limitation of AI in making valuebased moral decisions lies with the lack of moral emotions. Although AI programs can improve efficiency in data processing and analysis, they do not feel awe, excitement, empathy, compassion, gratitude, guilt, shame, pride, disgust, regret, and moral outrage. These emotions are essential in making moral decisions to promote and stabilize cooperative behaviors that are dependent upon socially shaped ideas of right and wrong (Greene, 2013). Currently, AI has not considered the role of feelings and emotions in human mental processes in decision making (Damasio, 2019). Leaders' feelings and emotions - from passion to compassion, from empathy to disgust, and from guilt and regret - are part of intuition that leaders rely on when making fast decisions by following gut feelings (Wang, 2020). AI may be able to read human emotions through facial expression and body language, but AI has not been able to empathize with the suffering of others, which is essential in making moral decisions to restore and uphold justice (Decety and Cowell, 2015). School leaders ask, "What is the right thing to do?" AI programs, on the other hand, ask, "Based on the patterns in data and the probability of options, what is the 
most appropriate next action?" Unlike humans, AI programs are not motivated by compassion and empathy. A case in point was that a district superintendent was charged with a felony because she lied to a clinic that a student was her son so that the student, who had no health insurance, could receive medical treatment (Mitchell, 2019). The superintendent broke the law so that the student could receive healthcare—-fraudulently. But compared to doing nothing, the superintendent acted out of compassion for the student.

The potential clash between value-based moral decision making and AI-assisted datadriven decision making lies with how human brains work when making decisions. Making moral decisions activates the brain's default mode network (DMN), which is associated with emotion processing and social interactions (Buckner et al., 2008). The DMN does not work simultaneously with another brain network called the task positive network (TPN), which is activated when leaders perform the tasks that demand logical reasoning and causal reasoning (Jack et al., 2013). The DMN and TPN work like the "two ends of a seesaw" (Lieberman, 2013, p. 27): when the DMN is activated, the TPN is suppressed, and vice versa. When the DMN is activated, people empathize and have moral concerns for others. When the TPN is activated, people focus attention on accomplishing clearly defined goals (Schweitzer et al., 2004). An example is that some school leaders disregarded the moral value of not lying to students and parents, and chose to purposely withhold information of opting out of state standardized tests from parents so that the schools and districts could meet the $95 \%$ participation rate required by the Every Student Succeeds Act (Wang, 2017). The tradeoff between the DMN and TPN poses a neural constraint for school leaders who cannot be "both genuinely empathetic and analytic at the same time" (Boyatzis et al., 2014, p. 6). Such an antagonistic relationship has been supported by empirical research in educational leadership. For example, school leaders were found unable to 
follow the ethical principles of care and fairness at the same time (Eyal et al., 2011). School closure is another example. The funding of American public schools is so closely linked to student enrollment counts. The data and evidence on budgetary constraints, low student enrollment, and low ratings in a state's accountability system were usually used to make the decision of closing a school. However, such decisions gave rise to community protests. Some argued that the decisions of school closure produced spatial injustice, as the closures disproportionately affected low-income communities and communities of color live, limiting their access to equitable education (Tieken and Auldridge-Reveles, 2019).

No matter how massive the amount of data is, data and evidence do not guarantee the moral premise of a decision (Wang, 2019, 2020). In this manner, AI-assisted data-driven decision making and moral decision making might be incompatible simultaneously, as evidenced by leadership literature which asserts that "the demands of both the organization and the profession [educational leadership] interfere with enactment of caring" (Marshall et al., 1996, p. 271). People's innate sense of caring, kindness, cooperation, and fairness are part of intuition (Gazzaniga, 2011). Intuition is a better guide than deliberation to make moral decisions when conflicts of interest are involved (Fehr and Gächter, 2002), as evidenced by the superintendent who took the risk of breaking the law to help the student in need of medical care. For this reason, AI can only play a complementary role in decisions made by leaders and organizational members. Proceeding with care produces lasting results on people.

Taken together, both leaders' decision making, and organizational decision making, are best handled by using a blend of both data-driven, evidence-informed decision making and value-based moral decision making. Given the tradeoff of DMN-TPN brain networks, reliance on either decision-making approach alone is insufficient. The human-AI symbiosis in decision 
making can play out in two ways. First, in an accountability-driven, data-rich school organization where information is not scarce, but time to attend to it is, AI is well-positioned to process and analyze vast amounts of data, functioning as an extended brain to make data-driven, evidenceinformed decisions. Second, the strengths of AI can free up people's time so that they can use human intelligence to focus more on making value-based moral decisions. Indeed, many decisions are not merely technical ones, but the ones that involve moral values, thus rendering human judgment indispensable.

\section{Recommendations}

In this section, building on the role of AI in educational leadership, particularly in decision making at both individual level and organizational level, I provide two recommendations for school leaders and education policymakers who navigate the uncharted waters and wrestle with the thorny challenges of AI.

\section{Keep a Watchful Eye on Biases}

It is recommended that school leaders keep a watchful eye on biases. Alarming examples of biases in AI have been well documented (Zou and Schiebinger, 2018). Take gender bias as an example. Since more males are in science, technology, engineering, and mathematics fields, Google Translate defaults to male pronouns even while translating gender-neutral language (Prates et al., 2020). Using Google Search to find job opening ads, men were five times more likely than women to be offered ads for high-paying executive jobs (Datta et al., 2015). School leaders need to be vigilant about the similar biases that may creep into AI developed to assist leaders' decision-making.

Examples of racial bias in algorithms abound as well. A widely used algorithm that guided healthcare decisions by recommending patients for health interventions has been 
discriminating against Black patients. Specifically, Black patients who were assigned the same level of risk by the algorithm were sicker than White patients. The racial bias in the algorithm reduced more than $50 \%$ of Black patients for appropriate healthcare (Obermeyer et al., 2019). This racial bias derived from the algorithm that used health costs as a proxy for health needs, but unequal access to healthcare meant that less money was spent on Black patients who had the same level of need than for White patients. Thus, the algorithm falsely concluded that Black patients were healthier than equally sick White patients. This is a cautionary tale if a similar mistake is made in education, such as using an inappropriate proxy for student learning needs or minority teachers' need for professional development. In making hiring decisions, AI programs may amplify racial bias in the United States by favoring White job candidates because most leadership positions were held by White school leaders.

An example of how algorithms intersect gender and race is that the gender-identification algorithms tend to misclassify darker-skinned females at a higher rate than the rest of the population (Buolamwini and Gebru, 2018). Some schools have or plan to adopt facial recognition software for school safety. It is disconcerting that facial recognition has been notoriously inaccurate at identifying people of color, women, and children. More troubling, some risk-assessment AI algorithms that are used to calculate criminal sentences tend to make harsher predictions about Black defendants than White ones. Such biases can lead AI to make discriminatory, biased decisions against the residents in poorer or minority neighborhoods (Osoba and Welser IV, 2017). In education, classrooms with mostly English-language learners may not respond to suggestions generated by AI that were built on the data made up primarily of native speakers. Similar biases may arise when the difference between rural classrooms and urban classrooms is dismissed (Herold and Schwartz, 2017). 
The sources of biases, as noted earlier, lie with biases that already existed in the data used to build AI programs. As a result, school leaders need to be cautious as AI becomes part of their decision-making process. One way to address biases in AI is to identify when it is appropriate for an algorithm to use gender and race information. In some settings, such as screening job application materials and grading student homework, it might be desirable for the algorithm to explicitly ignore the gender and race of an applicant. In other AI applications, such as image/voice recognition, it might be desirable to leverage gender characteristics to achieve the best accuracy possible across all subpopulations. Educational leaders need to be on the lookout for biases in AI used in schools. In school leaders' AI-assisted decision making, AI may bias against students from minorities and from low socioeconomic families, and students with special needs. AI may also have racial and gender biases in teacher/staff hiring. Even worse, the biases, in turn, could exacerbate education inequities, generating a vicious circle that entrenches people as the victims of biases. Without transparency or oversight, $\mathrm{AI}$ is at particular risk of amplifying existing biases in decisions made by leaders and organizational members. Being aware of the lurking biases in AI is the first step for school leaders to contemplate how to use AI in their work to counter biases instead of amplifying them.

\section{Mind Ethically Compromised Decisions}

It is further recommended that school leaders need to be mindful of ethically compromised decisions when using AI to inform decisions. Given the undesirable consequences of data-driven, evidence-informed decision making as noted earlier, education is inherently people-driven. People cannot be reduced to data points. When we make decisions in social settings, complexity reigns, and ambiguity grows. If data are the only factor taken into account in making moral decisions, AI may generate cold-hearted, emotionally detached decisions, creating 
an ethical minefield. When deciding about whether to close a school, if AI follows the utilitarian principle - maximizing the group interest and the greater good, the decisions of closing a school—due to the data on low student enrollment and low rating in a state's accountability system — could be interpreted by the community as a cold-hearted decision. To fulfill our moral obligations to students' well-being, we need a human touch, literally and figuratively. School leaders, rather than AI, should take the helm of caring for students and teachers, pouring our heart out, and empower teaching and learning in schools.

To mind ethically compromised decisions, it is important to ensure transparency of school leaders' decision making. To do so, the effectiveness of AI needs to be under public scrutiny. Transparency is crucial for building public trust in schools (Hoy and Tschannen-Moran, 1999). School leaders sometimes face up entrenched societal issues that have nothing to do with technology, but AI, as noted earlier, can potentially amplify existing biases. The public may ask school leaders, "Could you give an explanation of how AI reaches its decision?" The problem is since the algorithms and decisions are a black box, it is difficult, even to those who develop the AI algorithms, to really know how a decision is made.

AI Algorithms process the immense streams of data in ways that human brains are incapable of computing and processing. But an inherent limitation of AI is its explainability, particularly when AI makes decisions via the technical approaches of neural networks and deep learning (Coyle and Weller, 2020). AI is not programmed in a conventional way by specifying the steps of an algorithm. Instead, they are trained by showing them large numbers of examples of input-output pairs and adjusting their internal connection weights so that every input produces an output. Using the technical approach of a neural network, even AI developers have difficulty with explaining how the output is generated, just like humans sometimes having a hard time 
articulating how they reach a decision exactly. To overcome the AI "black box" problem, some scholars have advocated using algorithm transparency requirements to limit the biases that are often unintendedly encoded into those algorithms (Schulz and Raman, 2020). The guardrail of transparency in decision making is one way to build trust and ensure organizational justice in schools. School leaders can also invite stakeholders to leverage their insights and intuitions about both inputs and desired ends of $\mathrm{AI}$ in education.

Beyond the transparency of decisions powered by AI, school leaders also need to be concerned about the security and privacy of data used in AI systems. Missteps on the issues about cybersecurity and student privacy can have a life-long impact on students, teachers, and staff. Some school districts have already fallen victim to phishing scams and ransomware attacks, losing millions of taxpayer dollars and the personal data about children and teachers being comprised. School districts, which are data-rich and often lack robust cybersecurity, have emerged as an increasingly vulnerable target. Ill-intentioned hackers have learned that schoolswith their large repositories of data — can be exploited. In the United States, public schools are subject to federal laws (e.g., Every Student Succeeds Act) and state laws to collect a large amount of data, ranging from student performance data to what medications students take. Losing access to these data can be devastating, creating legal liability for school districts.

\section{Conclusion}

This position paper explores the role of AI in educational leadership. Specifically, I envisioned a future of the symbiotic role of human-AI decision making in educational organizations at both the leaders' individual decision-making level and the organizational decision making level. AI is a tool that school leaders can leverage for its efficiency and accuracy to assist in making well-defined data-driven, evidence-informed decisions. But AI does 
not handle uncertainty well. Yet uncertainty is inherent in school leaders' decision making. For example, AI is ill-equipped to address the uncertainty brought by the evolving COVID19pandemic and parents' opinion on whether to send their children back to school for face-toface instruction. AI is also ill-equipped to address the uncertainty brought by the fact that some features of an option are difficult to assess, such as hard-to-predict district revenue due to the loss of sales tax and property tax in the wake of COVID-19. In such cases, school leaders' decision making is better served by their moral values.

Furthermore, AI should not replace school leaders in making decisions as leaders' moral values that cannot be easily encoded in data. In the age of AI, blindly pursuing the cold logic of data is not just morally dubious; it can be downright dangerous. AI is not a plug-and-play technology with immediate returns in schools. It could be perilous to rely solely on those data to make decisions that would have a widespread influence on educators, students, and communities. Bear in mind that data work for people, not the other way around. Hard data and calculating algorithms must be blended with moral values and human warmth to promote kind, compassionate, and innovative schools.

Are school leaders willing to resist the temptation of merely looking for a quick fix that removes the messy details of building and maintaining social relationships with teachers, staff, and communities? Are school leaders willing to use freed-up time to engage with people in schools, understand the messy realities behind data, and treat people with respect, rather than demeaning and dehumanizing people to data points? If school leaders allow the value of data to override the value of the people whom the leaders serve, then the leaders justify replacing themselves with robot leaders who endow AI with all decision-making power. The pace of AI 
adoption in education shows no sign of slowing. As such, this position paper does not aim to make a final statement on this topic, but hopefully it stimulates further discourse. 


\section{References}

Babic, B., Chen, D.L., Evgeniou, T. and Fayard, A. (2020), "A better way to onboard AI", Harvard Business Review, Vol. 98 No. 4, pp. 56-65.

Bostrom, N. (2016), Superintelligence: Paths, Dangers, Strategies, Oxford University Press, Cary, NC.

Boyatzis, R.E., Rochford, K. and Jack, A.I. (2014), “Antagonistic neural networks underlying differentiated leadership roles", Frontiers in Human Neuroscience, Vol. 8, Article No. 114, pp. 1-15.

Bryant, J., Heitz, C., Sanghvi, S. and Wagle, D. (2020), "How artificial intelligence will impact K-12 teachers", available at https://www.mckinsey.com/industries/social-sector/ourinsights/how-artificial-intelligence-will-impact-k-12-teachers (accessed 8 September 2020)

Buchanan, L. and O'Connell, A. (2006), “A brief history of decision making”, Harvard Business Review, Vol. 84 No. 1, pp. 32.

Buckner, R.L., Andrews-Hanna, J.R. and Schacter, D.L. (2008), “The brain's default network: Anatomy, function, and relevance to disease", Annals of the New York Academy of Sciences, Vol. 1124, pp. 1-38.

Buolamwini, J. and Gebru, T. (2018). "Gender shades: Intersectional accuracy disparities in commercial gender classification", in Friedler, S.A. and Wilson, C. (Ed.s.), 2018 Conference on fairness, accountability and transparency, New York, NY, pp. 77-91.

Bushweller, K. (2020), “Teachers, the robots are coming. But that's not a bad thing”, Education Week, Vol. 39 No. 7, pp. 8-9. 
Castelvecchi, D. (2016), “Can we open the black box of AI?”, Nature, Vol. 538 No. 7623, pp. 20-23.

Choo, C.W. (1991), "Towards an information model of organizations", The Canadian Journal of Information Science, Vol. 16 No. 3, pp. 32-62.

Courtland, R. (2018), "Bias detectives: The researchers striving to make algorithms fair", Nature, Vol. 558 No. 7710, pp. 357-357.

Coyle, D. and Weller, A. (2020), “'Explaining' machine learning reveals policy challenges”, Science, Vol. 368 No. 6498, pp. 1433-1434.

Damasio, A.R. (2019), The Strange Order of Things: Life, Feeling, and the Making of Cultures. Vintage, New York, NY.

Dastin, J. (2018). “Amazon scraps secret AI recruiting tool that showed bias against women”, Reuters, 9 October, available at https://www.reuters.com/article/us-amazon-com-jobsautomation-insight/amazon-scraps-secret-ai-recruiting-tool-that-showed-bias-againstwomen-idUSKCN1MK08G (accessed 8 September 2020)

Datta, A., Tschantz, M.C. and Datta, A. (2015), “Automated experiments on ad privacy settings: A tale of opacity, choice, and discrimination", Proceedings on privacy enhancing technologies, Vol. 2015 No. 1, pp. 92-112.

Davenport, T.H. (2018), "The AI Advantage: How to Put the Artificial Intelligence Revolution to Work. MIT Press, Cambridge, MA.

Decety, J. and Cowell, J.M. (2015), “Friends or foes: Is empathy necessary for moral behavior?”, Perspectives on Psychological Science, Vol. 9 No. 4, pp. 525-537. 
Dexter, S., Clement, D., Moraguez, D. and Watson, G.S. (2020), “(Inter) Active learning tools and pedagogical strategies in educational leadership preparation", Journal of Research on Leadership Education, Vol. 15 No. 3, pp. 173-191.

Duke, D. (2019), "Judgment and the preparation of educational leaders", Journal of Research on Leadership Education, Vol. 14 No. 3, pp. 191-211.

Eyal, O., Berkovich, I. and Schwartz, T. (2011), "Making the right choices: Ethical judgments among educational leaders", Journal of Educational Administration, Vol. 49 No. 4, pp. 396-413.

Fehr, E. and Gächter, S. (2002), “Altruistic punishment in humans”, Nature, Vol. 415 No. 6868, pp. 137-140.

Frank, M.R., Autor, D., Bessen, J.E., Brynjolfsson, E., Cebrian, M., Deming, D. J., ... and Wang, D. (2019), "Toward understanding the impact of artificial intelligence on labor", Proceedings of the National Academy of Sciences, Vol. 116 No. 14, pp. 65316539.

Frick, W.C. (2009), "Principals' value-informed decision making, intrapersonal moral discord, and pathways to resolution: The complexities of moral leadership praxis", Journal of Educational Administration, Vol 47 No. 1, pp. 50-74.

Frick, W.C., Faircloth, S.C. and Little, K.S. (2013). "Responding to the collective and individual 'best interests of students': Revisiting the tension between administrative practice and ethical imperatives in special education leadership", Educational Administration Quarterly, Vol. 49 No. 2, pp. 207-242.

Gazzaniga, M. (2011), Who's in Charge? Free Will and the Science of the Brain, HarperCollins, New York, NY. 
Ghahramani, Z. (2015), "Probabilistic machine learning and artificial intelligence”, Nature, Vol. 521 No. 7553, pp. 452-459.

Greene, J.D. (2013), Moral Tribes: Emotion, Reason, and the Gap Between Us and Them. Penguin Press, New York, NY.

Griffiths, D.E. (1959), Administrative Theory. Prentice Hall, Englewood Cliffs, NJ.

Herold, B. (2019), “Forty percent of elementary school teachers' work could be automated by 2030, McKinsey Global Institute Predicts”, Education Week, 4 June, available at https://blogs.edweek.org/edweek/DigitalEducation/2019/06/women_future_of_work_mc kinsey.html (accessed on 8 September 2020)

Herold, B. and Schwartz, S. (2017), “Algorithmic bias a rising concern for K-12 ed-tech field”, Education Week, Vol. 36 No. 28, pp. 8.

Hoy, W.K. and Tschannen-Moran, M. (1999), "Five faces of trust: An empirical confirmation in urban elementary schools", Journal of School leadership, Vol. 9 No. 3, pp. 184-208.

Jack, A.I., Dawson, A.J. and Norr, M.E. (2013), "Seeing human: Distinct and overlapping neural signatures associated with two forms of dehumanization", NeuroImage, Vol. 79 No. 1, pp. 313-328.

Jacob, B., Rockoff, J., Taylor, E.S., Lindy, B. and Rosen, R. (2019). "Improving selection of job applicants: Harnessing resume, interview and recommender signals for K12 teaching”, Paper Presented at the Annual Meeting of American Economic Association. Atlanta, GA. Available at https://www.aeaweb.org/conference/2019/preliminary/624

Jarrahi, M.H. (2018), “Artificial intelligence and the future of work: Human-AI symbiosis in organizational decision making”, Business Horizons, Vol. 61 No. 4, pp. 577-586.

Kahneman, D. (2013), Thinking, Fast and Slow. Farrar, Straus and Giroux, New York, NY. 
Klein, A. (2019). “District's plan to use facial recognition tech for safety raises big privacy concerns", available at http://blogs.edweek.org/edweek/DigitalEducation/2019/05/surveillance-software-facialnew-york-safety.html?cmp=eml-enl-eunews $2 \& M=58846469 \& U=1338430 \& U U I D=338968 a 915 f 082 d 3 f 63 f 31 d a e 7 c 1 d 621$ (accessed on 8 September 2020)

Lammers, J., Stoker, J.I., Rink, F. and Galinsky, A.D. (2016), “To have control over or to be free from others? The desire for power reflects a need for autonomy", Personality and Social Psychology Bulletin, Vol. 42 No. 4, pp. 498-512.

Lieberman, M.D. (2013), Social: Why Our Brains Are Wired to Connect. Crown, New York, NY.

Marion, R. and Uhl-Bien, M. (2001), "Leadership in complex organizations", The Leadership Quarterly, Vol. 12 No. 4, pp. 389-418.

Marshall, C., Patterson, J.A., Rogers, D.L. and Steele, J.R. (1996), “Caring as career: An alternative perspective for educational administration”, Educational Administrative Quarterly, Vol. 32 No. 2, pp. 271-2914.

Mitchell, P.A. (2019), Ethical Decision-Making: Cases in Organization and Leadership. Myers Education Press, Gorham, ME.

National Center for Education Statistics. (2019), "Digest of Education Statistics", available at https://nces.ed.gov/programs/digest/d19/tables/dt19_212.08.asp (accessed on 8 September 2020) 
Obermeyer, Z., Powers, B., Vogeli, C. and Mullainathan, S. (2019), "Dissecting racial bias in an algorithm used to manage the health of populations", Science, Vol. 366 No. 6464, pp. 447-453.

Osoba, O.A. and Welser IV, W. (2017), “An intelligence in our image: The risks of bias and errors in artificial intelligence", available at https://www.rand.org/pubs/research_reports/RR1744.html (accessed on 8 September 2020)

Prates, M.O., Avelar, P.H. and Lamb, L.C. (2020), “Assessing gender bias in machine translation: A case study with google translate", Neural Computing and Applications, Vol. 32, pp. 6363-6381.

Russell, S. (2019), Human Compatible: Artificial Intelligence and the Problem of Control. Penguin, London, UK.

Sara, N.B., Halland, R., Igel, C. and Alstrup, S. (2015), "High-school dropout prediction using machine learning: A Danish large-scale study", in Proceedings of European Symposium on Artificial Neural Networks, Computational Intelligence, Bruges, Belgium, April 2223-24, 2015, pp. 319-324.

Schulz, W.F. and Raman, S. (2020), The Coming Good Society. Harvard University Press, Cambridge, MI.

Schweitzer, M.E., Ordóñez, L. and Douma, B. (2004), “Goal setting as a motivator of unethical behavior", Academy of Management Journal, Vol. 47 No. 3, pp. 422-432.

Sergiovanni, T.J. (1992), "Reflections on administrative theory and practice in schools", Educational Administration Quarterly, Vol. 28, pp. 304-313. 
Shapiro, J.P. and Stefkovich, J.A. (2016), Ethical Leadership and Decision Making in Education: Applying Theoretical Perspectives to Complex Dilemmas. Routledge, New York, NY.

Simon, H.A. (1965), The Shape of Automation for Men and Management. Harper \& Row, New York, NY.

Simon, H.A. (1972), “Theories of bounded rationality”, Decision and Organization, Vol. 1 No. 1, pp. 161-176.

Simon, H.A. (2013), Administrative Behavior. Simon and Schuster, New York, NY.

Sorensen, L.C. (2019), “'Big data' in educational administration: An application for predicting school dropout risk", Educational Administration Quarterly, Vol. 55 No. 3, pp. 404-446.

Sparks, S.D. (2017), “Teachers' jobs aren't going away, but they could be different”, available at https://www.edweek.org/ew/articles/2017/09/27/how-intelligent-tutors-could-transformteaching.html (accessed on 8 September 2020)

Tarter, C.J. (1998), “Toward a contingency theory of decision making”, Journal of Educational Administration, Vol. 36 No. 3, pp. 212-228.

Tieken, M.C. and Auldridge-Reveles, T.R. (2019), "Rethinking the school closure research: School closure as spatial injustice", Review of Educational Research, Vol. 89 No. 6, pp. 917-953.

Ullman, S. (2019), "Using neuroscience to develop artificial intelligence”, Science, Vol. 363 No. 6428, pp. 692-693.

Wang. Y. (2016), "Big opportunities and big concerns of big data in education”, TechTrends, Vol. 60 No. 4, pp. 381-384. 
Wang, Y. (2017), "Education policy research in the big data era: Methodological frontiers, misconceptions, and challenges", Education Policy Analysis Archives, Vol. 25 No. 94, pp. 1-24.

Wang, Y. (2017). "The social networks and paradoxes of the opt-out movement amid the Common Core State Standards implementation”, Education Policy Analysis Archives, Vol. 25 No. 34, pp. 1-27.

Wang, Y. (2019), "Is data-driven decision making at odds with moral decision making? A critical review of school leaders' decision making in the era of school accountability", Values and Ethics in Educational Administration, Vol. 14 No. 2, pp. 1-9.

Wang, Y. (2020), “When artificial intelligence meets educational leaders' data-informed decision making: A cautionary tale", Studies in Educational Evaluation, available at: https://doi.org/10.1016/j.stueduc.2020.100872 (accessed 11 January 2021)

Wang, Y. (2021), "What is the role of emotions in educational leaders' decision making? Proposing an organizing framework", Educational Administration Quarterly, available at: https://doi.org/10.1177/0013161X20938856 (accessed 11 January 2021)

Weiner, J. M. (2016), “Under my thumb: Principals' difficulty releasing decision-making to their instructional leadership team”, Journal of School Leadership, Vol. 26 No. 2, 334-364.

Zeira, J. (2018), “Workers, machines, and economic growth”, The Quarterly Journal of Economics, Vol. 113, No. 4, pp. 1091-1117.

Zou, J. and Schiebinger, L. (2018), “AI can be sexist and racist—it's time to make it fair", Nature, Vol. 559, pp. 324-326. 